\title{
Gemini 表面活性剂烷烃尾链在吸附和聚集过程中的疏水协同效应
}

\author{
游毅 邓永淑李二军裴晓梅赵剑曦* \\ (福州大学化学化工学院, 胶体与界面化学研究所, 福州 350108)
}

\begin{abstract}
摘要： 以表面张力法测定了系列 Gemini 表面活性剂 $m-6-m$ 以及对应单体表面活性剂 $\mathrm{C}_{m} \mathrm{TABr}$ 的临界胶束浓 度 $(\mathrm{cmc})$ 和降低水表面张力 $20 \mathrm{mN} \cdot \mathrm{m}^{-1}$ 需要的浓度 $\left(\mathrm{p} C_{20}\right)$. 比较这些参数表明 $m-6-m$ 胶束化和在界面吸附的能力 均强于 $\mathrm{C}_{m} \mathrm{TABr}$, 这被归结为 Gemini 表面活性剂烷烃尾链间的疏水协同效应. 与不对称 Gemini 表面活性剂 126- $m$ 比较, 对称的 Gemini 结构更有利于表面活性剂的聚集和吸附.
\end{abstract}

关键词：Gemini 表面活性剂；六亚甲基联接链；烷烃尾链疏水协同效应；表面张力 中图分类号: $\mathrm{O} 648$

\section{Hydrophobic Synergism between the Alkyl Tails of Gemini Surfactants during Adsorption and Aggregation}

\author{
YOU Yi DENG Yong-Shu LI Er-Jun PEI Xiao-Mei ZHAO Jian-Xi* \\ (Institute of Colloid and Interface Chemistry, College of Chemistry and Chemical Engineering, \\ Fuzhou University, Fuzhou 350108, P. R. China)
}

\begin{abstract}
The critical micelle concentration $(\mathrm{cmc})$ and the concentration reducing $20 \mathrm{mN} \cdot \mathrm{m}^{-1}$ of water surface tension $\left(\mathrm{p} C_{20}\right)$ by the Gemini surfactant series $(m-6-m)$ and the corresponding monomers $\left(\mathrm{C}_{m} \mathrm{TABr}\right)$ were determined using surface tension measurements. Comparison between the active parameters indicates that the Gemini surfactants have a stronger micellization and adsorption ability than $\mathrm{C}_{m} \mathrm{TABr}$, which is attributed to the hydrophobic synergism between the alkyl tails of the Gemini surfactants. The effects of dissymmetry in the Gemini surfactants (12-6- $m$ ) on the micellization and adsorption were also discussed. The results showed that the Gemini surfactant with a symmetric structure is more effective in association and adsorption than that with a dissymmetric structure.
\end{abstract}

Key Words : Gemini surfactant; Hexamethylene spacer; Hydrophobic synergism between alkyl tails;

Surface tension

In the past decade, Gemini surfactants have attracted great interest since these surfactants possess more predominant surface activity than traditional single-chain surfactants ${ }^{[1]}$. This was attributed to the special molecular structure of Gemini surfactants different from conventional surfactants, in which the spacer connecting two hydrophilic headgroups plays a key role ${ }^{[1-4]}$. Summarily, the spacer (a) shields the hydrophobic core of the aggregate from contact with water, (b) constrains the distance between the headgroups, thus imposing non-uniformity in charge distri- bution at the aggregate surface, and (c) can be partially buried inside the micelle core provided its length and the molecular interactions allows $\mathrm{it}^{[1,5]}$. A typical example is alkanediyl- $\alpha, \omega$-bis (dimethylalkylammonium bromide) surfactants. This family of Gemini surfactants is generally referred to as $m-s-m$ and has a flexible polymethylene spacer chain connecting the two quaternary ammonium headgroups. For 12-s-12 series, an irregular critical micelle concentration ( $\mathrm{cmc}$ ) varys with $s$, i.e., the cmc increases with $s$ from 2 to 5 then decreases with further increasing $s$ and

Received: January 13, 2010; Revised: March 23, 2010; Published on Web: May 13, 2010.

"Corresponding author. Email: jxzhao.colloid@fzu.edu.cn; Tel: +86-591-22866338.

The project was supported by the National Natural Science Foundation of China $(20673021,20873024)$ and Professor Foundation of Fuzhou

University, China (2008-XY-5).

国家自然科学基金(20673021, 20873024)和福州大学教授基金(2008-XY-5)资助项目

(C) Editorial office of Acta Physico-Chimica Sinica 
the maximum appears at $s \sim 5^{[2]}$, and strong salt $\operatorname{effect}^{[6]}$ has been attributed to the above spacer effects. The bending of the long polymethylene spacer chain toward the alkyl tail-side was also found by several groups ${ }^{[3,7-8]}$.

Besides these effects of the spacer chain, we believe that the hydrophobic interaction between the alkyl tails should be strengthened during the adsorption and the aggregation. For example, 12-6-12 has a hexamethylene spacer between the two quaternary ammonium headgroups and its stretched length is $0.889 \mathrm{~nm}$ calculated by the formula $d_{s}=0.127(s+1) \mathrm{nm}^{[3]}$. This value is almost identical to the electrostatic equilibrium distance (ca $0.9 \mathrm{~nm}^{[3]}$ ) between the two headgroups of alkyltrimethylammonium bromides packed on the micelle. This indicates the assumption of the fully stretched hexamethylene spacer is reasonable under the electrostatic repulsion of the two ionic headgroups. This seems to mean that $12-6-12$ is a simple dimeric form of $\mathrm{C}_{12} \mathrm{TABr}$ through a hexamethylene spacer connecting two quaternary ammonium headgroups. However, cmc of 12-6-12 (1.12 $\mathrm{mmol} \cdot \mathrm{L}^{-1}$ at $\left.25{ }^{\circ} \mathrm{C}^{[7]}\right)$ was found to be one order of magnitude lower than that of $\mathrm{C}_{12} \mathrm{TABr}\left(16 \mathrm{mmol} \cdot \mathrm{L}^{-1}\right.$ at $\left.25{ }^{\circ} \mathrm{C}^{[9]}\right)$. This fact indicates that the hydrophobic interaction between the alkyl tails should be strengthened during the aggregation. However, this viewpoint was less stressed so far $^{[10-11]}$. In the present investigation, we compare the self-assembly behavior of a series of Gemini surfactants $m-6-m$ with the corresponding monomers $\mathrm{C}_{m} \mathrm{TABr}$ in order to reveal the hydrophobic synergism between the alkyl chains of Gemini surfactants. Another series of Gemini surfactants 12-6- $m$ is also introduced to discuss the effect of dissymmetric structure of Gemini molecule on the self-assembly.

\section{Experimental}

\subsection{Materials}

The chemical structures of hexanediyl- $\alpha, \omega$-bis (dimethylalkylammonium bromide) and hexanediyl- $\alpha$-dimethyldodecylammonium- $\alpha$-dimethylalkylammonium dibromides, which are referred below as $m-6-m(m=8,10,12,14,16)$ and 12-6- $m(m=8,10,14$, 16), respectively, are represented in Scheme 1.

The $m-6-m$ series were synthesized by the reaction of $N, N, N$ alkyldimethylamine with $\alpha, \omega$-dibromoalhexane, which was first reported by Zana et al. ${ }^{[2]}$. The 12-6- $m$ series were synthesized with the method reported by Bai et al. ${ }^{[12]}$. The purity of the $m-s$ $m$ and 12-6- $m$ was checked by elemental analysis and ${ }^{1} \mathrm{H}$ NMR

$$
{ }_{m-6-m} \mathrm{CH}_{3}-{\stackrel{\mathrm{N}}{\mathrm{N}^{+}-6-m}-\left(\mathrm{CH}_{2}\right)_{6}-\mathrm{N}_{\mathrm{C}_{m} \mathrm{H}_{2 m+1}}^{\mathrm{CH}_{3}}-\mathrm{CH}_{3} \cdot 2 \mathrm{Br}^{-}}_{\mathrm{CH}_{3}-\mathrm{N}^{+}-\left(\mathrm{CH}_{2}\right)_{6}-\mathrm{N}_{\mathrm{C}^{+}-}^{\mathrm{CH}_{3}}}^{\mathrm{CH}_{3}} \cdot 2 \mathrm{CH}^{-}
$$

Scheme 1 Molecular structures of $m-6-m$ and 12-6- $m$ spectroscopy. Alkyltrimethylammonium bromide $\left(\mathrm{C}_{m} \mathrm{TABr}\right)$ was purchased from Sigma and used as received. Water used was Milli-Q grade.

\subsection{Method}

Surface tension of the solutions was measured by du Noüy ring method using tensionmeter (CHAN DCA-315, America). The circumference of the ring is $5.930 \mathrm{~cm}$. The ratio of the outside radius to the radius of the ring cross section $(R / r)$ is 53.1218. From the semilogarithmic plot of surface tension versus surfactant concentration, $\mathrm{cmc}$, the minimum surface tension at the $\mathrm{cmc}\left(\gamma_{\mathrm{cmc}}\right)$ and the concentration required to reduce $20 \mathrm{mN}$. $\mathrm{m}^{-1}$ of water surface tension $\left(\mathrm{p} C_{20}\right)$ can be obtained.

\section{Results and discussion}

\subsection{Surface activity of symmetric $m-6-m$ series}

As mentioned in Introduction, the Gemini surfactant $m-6-m$ looks like simple dimer of $\mathrm{C}_{m} \mathrm{TABr}$ through a hexamethylene spacer since the stretched length of this spacer chain is close to the electrostatic equilibrium distance between the two headgroups of $\mathrm{C}_{m} \mathrm{TABr}$ packed on the micelle. In this section, we compare the surface activity of $m-6-m$ with that of the corresponding monomer surfactants $\mathrm{C}_{m} \mathrm{TABr}$.

A typical surface tension plot of symmetric 12-6-12 is shown in Fig.1. The break point characterizes $\mathrm{cmc}$, which reflects the ability of surfactant forming micelles. $\gamma_{\mathrm{cmc}}$ and $\mathrm{p} C_{20}$ characterize the effectiveness and the efficiency of surfactant in surface tension reduction, respectively ${ }^{[9]}$. The maximum surface excess of surfactant $\Gamma_{\max }$ at the cmc can be calculated by Gibbs formula:

$$
\Gamma_{\max }=-\frac{1}{2.303 n R T} \frac{\mathrm{d} \gamma}{\mathrm{d} \lg C}
$$

from which the minimum area per molecule $\left(A_{\min }\right)$ at the interface is calculated by following formula:

$$
A_{\min }=\frac{1}{N_{\mathrm{A}} \Gamma_{\max }}
$$

where $N_{\mathrm{A}}$ is Avogardo constant. These parameters are listed in Table 1 .

Fig.2 shows the plots of $1 \mathrm{n}$ cmc versus $m$ (the number of the carbon atoms of the alkyl tail) for symmetric $m-6-m$ and $\mathrm{C}_{m} \mathrm{TABr}$, which exhibit good linear variation. This linear relationship has been known to satisfy the following formula ${ }^{[9]}$

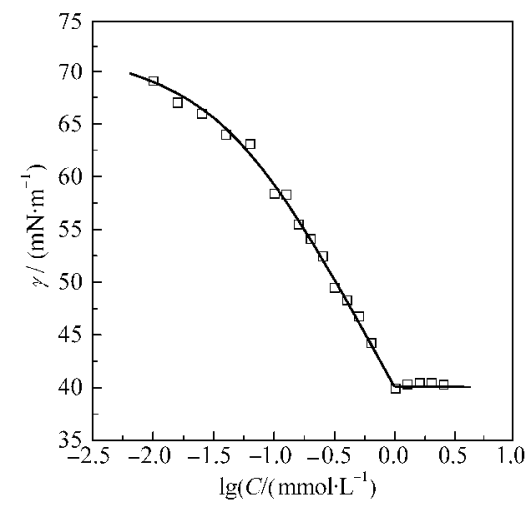

Fig.1 Semilogarithmic plot of surface tension $(\gamma)$ as a function of surfactant concentration $(C)$ for 12-6-12 
Table 1 Activity parameters of symmetric $m-6-m$, dissymmetric $12-6-m$, and $\mathrm{C}_{m} \mathrm{TABr}$ at $25{ }^{\circ} \mathrm{C}$

\begin{tabular}{|c|c|c|c|c|c|c|c|}
\hline System & $\mathrm{cmc}\left(\mathrm{mmol} \cdot \mathrm{L}^{-1}\right)$ & $\Delta G_{\mathrm{mic}}^{\ominus} /\left(\mathrm{kJ} \cdot \mathrm{mol}^{-1}\right)$ & $\mathrm{p} C_{20}$ & $\Delta G_{\text {add }}^{\ominus} /\left(\mathrm{kJ} \cdot \mathrm{mol}^{-1}\right)$ & $\gamma_{\mathrm{cmc}} /\left(\mathrm{mN} \cdot \mathrm{m}^{-1}\right)$ & $10^{10} \Gamma_{\max } /\left(\mathrm{mol} \cdot \mathrm{cm}^{-2}\right)$ & $A_{\min } / \mathrm{nm}^{2}$ \\
\hline $\mathrm{C}_{8}-6-\mathrm{C}_{8}$ & 61.7 & -20.6 & 1.88 & -20.7 & 39.8 & 1.51 & 1.10 \\
\hline $\mathrm{C}_{10}-6-\mathrm{C}_{10}$ & 6.21 & -27.2 & 2.87 & -26.4 & 39.8 & 1.54 & 1.08 \\
\hline $\mathrm{C}_{12}-6-\mathrm{C}_{12}$ & 1.03 & -32.4 & 3.61 & -30.6 & 40.3 & 1.65 & 1.00 \\
\hline $\mathrm{C}_{14}-6-\mathrm{C}_{14}$ & 0.16 & -37.8 & 4.28 & -34.4 & 40.5 & 2.29 & 0.72 \\
\hline $\mathrm{C}_{16}-6-\mathrm{C}_{16}$ & 0.0252 & -43.2 & 4.70 & -36.8 & 44.8 & 2.31 & 0.71 \\
\hline $\mathrm{C}_{12}-6-\mathrm{C}_{8}$ & 1.54 & -31.3 & 3.36 & -29.1 & 38.6 & 1.95 & 0.85 \\
\hline $\mathrm{C}_{12}-6-\mathrm{C}_{10}$ & 1.11 & -32.2 & 3.46 & -29.7 & 39.6 & 1.97 & 0.84 \\
\hline $\mathrm{C}_{12}-6-\mathrm{C}_{14}$ & 0.18 & -37.5 & 4.19 & -33.9 & 39.7 & 2.51 & 0.66 \\
\hline $\mathrm{C}_{12}-6-\mathrm{C}_{16}$ & 0.077 & -40.0 & 4.49 & -35.6 & 41.3 & 2.56 & 0.65 \\
\hline $\mathrm{C}_{8} \mathrm{TABr}$ & $(140)^{\mathrm{a}}$ & & & & & & \\
\hline $\mathrm{C}_{10} \mathrm{TABr}$ & $67.6(68)^{a}$ & -12.8 & 1.65 & -19.4 & 39.5 & 3.07 & 0.53 \\
\hline $\mathrm{C}_{12} \mathrm{TABr}$ & $16.0(16)^{\mathrm{a}}$ & -15.6 & 2.19 & -22.5 & 39.1 & 3.24 & 0.52 \\
\hline $\mathrm{C}_{14} \mathrm{TABr}$ & $3.1(3.6)^{\mathrm{a}}$ & -18.7 & 3.06 & -27.4 & 35.4 & 3.42 & 0.49 \\
\hline $\mathrm{C}_{16} \mathrm{TABr}$ & $0.91(0.92)^{\mathrm{a}}$ & -21.0 & 3.52 & -30.0 & 37.3 & 3.46 & 0.48 \\
\hline
\end{tabular}

${ }^{a}$ The data in parentheses are from Ref.[9]. $C_{20}$ is in $\mathrm{mol} \cdot \mathrm{L}^{-1}$ for $\mathrm{p} C_{20}$.

$\ln \mathrm{cmc}=\frac{\Delta G_{\text {mic }}^{\ominus}\left(\mathrm{CH}_{2}\right)}{R T} m+\frac{\Delta G_{\text {mic }}^{\ominus}(w)+\delta}{R T}$

where $\omega$ is the moles of $\mathrm{H}_{2} \mathrm{O}$ per cubic decimeter for pure water at absolute temperature $T\left(\omega=55.5 \mathrm{~mol} \cdot \mathrm{L}^{-1}\right.$ at $\left.25{ }^{\circ} \mathrm{C}\right), \Delta G_{\text {mic }}^{\ominus}$ is the standard free energy of micellization, $\delta$ is a constant at given temperature and represents as a difference between $\Delta G_{\text {mic }}^{\ominus}\left(\mathrm{CH}_{3}\right)$ and $\Delta G_{\text {mic }}^{\ominus}\left(\mathrm{CH}_{2}\right)$. The slope reflects the contribution of a methylene group in the alkyl chain to micellization. As seen from Fig. 2 , the negative value of the slope (-0.94) of $m-6-m$ is greatly larger than that $(-0.65)$ of $\mathrm{C}_{m} \mathrm{TABr}$, indicating that the alkyl chains of the Gemini surfactants have larger tendency to aggregation than that of the single-chain $\mathrm{C}_{m} \mathrm{TABr}$. This clearly shows that though the spacer chain length of $m-6-m$ is close to the electrostatic equilibrium distance between the two headgroups of $\mathrm{C}_{m} \mathrm{TABr}$ packed on the micelle, the Gemini structure of $m-6-m$ molecule makes the hydrophobic effect of their alkyl chains remarkable in the micellization.

The $\mathrm{p} C_{20}$ that characterizes the efficiency of surfactant in surface tension reduction ${ }^{[9]}$ satisfies the similar formula

$$
\mathrm{p} C_{20}=\frac{-\Delta G_{\text {mic }}\left(\mathrm{CH}_{2}\right)}{2.3 R T} m+K_{2}
$$

where $K_{2}$ represents the increase in the free energy when the hy-

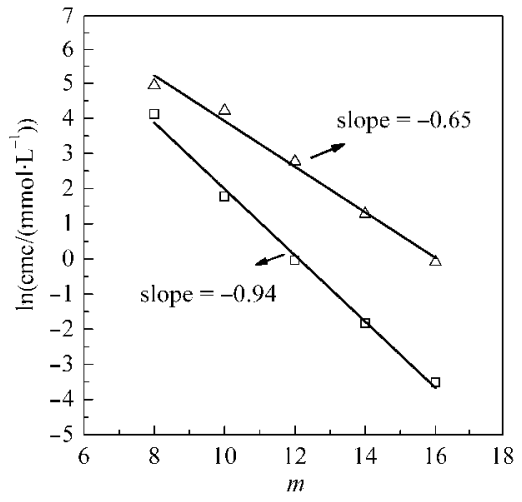

Fig.2 Comparison between the plots of $\ln$ cmc versus $m$ (the number of the carbon atoms of the alkyl tail) for symmetric $m$-6- $m(\square)$ and $C_{m} \operatorname{TABr}(\triangle)$ drophilic groups are moved into the interface. The results in Fig. 3 also give out the same information, i.e., a slope (0.35) for $m$-6$m$ is relatively larger than that $(0.32)$ for $\mathrm{C}_{m} \mathrm{TABr}$, indicating the stronger hydrophobic effect between the alkyl chains of the Gemini surfactants than the corresponding monomers in the adsorption.

$\Delta G_{\mathrm{mic}}^{\ominus}$ is related to the cmc by the following formulas:

$$
\begin{aligned}
\Delta G_{\mathrm{mic}}^{\ominus}=R T\left(0.5+K_{0}\right) \ln (\mathrm{cmc} / \omega) & -(R T / 2) \ln 2 \\
& \quad(\text { for Gemini surfactant })^{[13]}
\end{aligned}
$$$$
\Delta G_{\text {mic }}^{\ominus}=R T K_{0} \ln (\mathrm{cmc} / \omega) \quad{\text { (for traditional surfactant }{ }^{[9]}}^{[0}
$$

where $K_{0}$ is the degree of counterion association. The $K_{0}$ of 12 6-12 and $\mathrm{C}_{12} \mathrm{TABr}$ have been known to be $0.67^{[2]}$ and $0.77^{[14]}$, respectively. Both the values are used to calculate $\Delta G_{\text {mic }}^{\ominus}$ of $m$-6$m$ and $\mathrm{C}_{m} \mathrm{TABr}$ series regardless of the length of the alkyl tail. The data listed in Table 1 show the obviously larger negative values of $\Delta G_{\text {mic }}^{\ominus}$ in comparison with those of $\mathrm{C}_{m} \mathrm{TABr}$, indicating stronger tendency of the Gemini surfactants for micellization.

The standard free energy of adsorption at the surface pressure $\pi, \Delta G_{\text {ads }}^{\ominus}$, follows the formula:

$$
\Delta G_{\text {ads }}^{\ominus}=R T \ln \left(C_{w, \pi} J \omega\right)-\pi N_{\mathrm{A}} A_{\text {min }}
$$

At $\pi=52 \mathrm{mN} \cdot \mathrm{m}^{-1}$ (corresponding surfactant concentration is $\mathrm{C}_{20}$ ),



Fig.3 Comparison between the plots of $\mathrm{p} C_{20}$ versus $m$ for symmetric $m-6-m(\square)$ and $C_{m} \operatorname{TABr}(\triangle)$ 
$\Delta G_{\text {ads }}^{\ominus}$ can relate to the $\mathrm{p} C_{20}$ and the $A_{\text {min }}$ :

$$
\Delta G_{\text {ads }}^{\ominus}=-2.303 R T\left(\mathrm{p} C_{20, u}+\lg \omega\right)-20 N_{\AA} A_{\text {min }}
$$

The calculated $\Delta G_{\text {ads }}^{\ominus}$ also shows the larger negative values for $m-6-m$ than those for $\mathrm{C}_{m} \mathrm{TABr}$ (Table 1).

\subsection{Effect of dissymmetric structure of 12-6-m}

Similar to symmetric $m-6-m$, the dissymmetric $12-6-m$ contains a hexamethylene spacer linking the two quaternary ammonium headgroups but an alkyl tail is fixed at the length of 12 carbon atoms and another has variable length from 8 to 16 carbon atoms. As can be seen from Fig.4, the plots of both $1 \mathrm{n} \mathrm{cmc}$ and $\mathrm{p} C_{20}$ versus $m$ exhibit two linear regions with different slopes separating at $m=12$. At $m<12$, the $\ln \mathrm{cmc}$ and $\mathrm{p} C_{20}$ have almost no change with increasing $m$, meaning a very small contribution of increasing the number of carbon atoms in the short chain to both the micellization and the adsorption. In other words, the micellization and the adsorption of these compounds are mainly driven by the hydrophobic effect between the long alkyl chains. At $m>12$, the slopes of the straight lines for both the $1 \mathrm{n} \mathrm{cmc}$ and the $\mathrm{p}_{20}$ plots are smaller than those of the corresponding monomers, indicating that for the combination of two alkyl tails with different lengths (dissymmetric Geminis) the contribution of increasing methylene group to the micellization and to the adsorption is relatively smaller. This was also reflected in the binary mixture of traditional single-chain surfactants to some extent, for which two surfactants having the same lengths of the alkyl chains was found to have the synergism larger than those having different lengths of the alkyl chains ${ }^{[15]}$.


Fig.4 Plots of $\ln \mathrm{cmc}(\mathrm{a})$ and $\mathrm{p} C_{20}(\mathrm{~b})$ as a function of $m$ for dissymmetric 12-6-m
Compared the results of Fig.2 and Fig.3 with Fig.4, one can realize that the Gemini surfactants having the same lengths of alkyl chains (symmetric structure) can play a better role of the molecular structure in the aggregation and the adsorption than those having the different lengths of alkyl chains (dissymmetric structure)

\subsection{Structure of the adsorption layer}

As can be seen from Table 1, the average area $\left(A_{\text {min }}\right)$ of symmetric 10-6-10 or 12-6-12 occupied at the air/water interface is about twice $A_{\min }$ of the corresponding monomer $\mathrm{C}_{10} \mathrm{TABr}$ or $\mathrm{C}_{12} \mathrm{TABr}$. However, the $A_{\min }$ of 14-6-14 and 16-6-16 are greatly smaller than the expected twice values. This clearly shows the enhanced hydrophobic interaction between the alkyl tails of 146-14 and 16-6-16 and again indicates that Gemini structure of the amphiphilic molecule is favorable to the synergism between the alkyl tails though its spacer chain is close to the electrostatic equilibrium distance between the two headgroups of $\mathrm{C}_{m} \mathrm{TABr}$ packed on the micelle.

The smaller $A_{\min }$ corresponds to more tight arrangement of the adsorbed molecules at the air/water interface. In general, the tight and uniform arrangement of surfactant molecules at the air/water interface can result in smaller $\gamma_{\mathrm{cmc}}{ }^{[9]}$. However, it is surprised that 14-6-14 and 16-6-16 have rather large $\gamma_{\mathrm{cmc}}$ in comparison with that of $\mathrm{C}_{14} \mathrm{TABr}$ or $\mathrm{C}_{16} \mathrm{TABr}$. We recall our previous investigation where the effect of added salt on the adsorption and aggregation of 12-6-12 was found to be much stronger than on that of $\mathrm{C}_{12} \mathrm{TABr}^{[6]}$. This was attributed to the concentrated charge effect in the headgroups of 12-6-12, resulting in highly sensitive response to salt. This fact indicates that even though for 12-6-12, the hydrophobic interaction between the alkyl tails within the molecule may have been put the two quaternary heads close to some extent. That is to say that the real area of the head of 12-6-12 is perhaps smaller than the area calculated by the stretched length of the hexamethylene group. Therefore the apparent area that is twice the area of the corresponding monomer $\mathrm{C}_{12} \mathrm{TABr}$ is the result of the increased electrostatic repulsion between the ionic headgroups of 12-6-12. The gap between the occupied molecules at the air/water interface thus allows water molecules to fill, which results in the relatively high $\gamma_{\mathrm{cm}}$. In other words, the non-uniform arrangement of Gemini molecules at the air/water interface should be the reason leading to larger $\gamma_{\mathrm{cmc}}$. Obviously, this phenomenon is certainly more pronounced for 14-6-14 and 16-6-16 since they have stronger hydrophobic interaction between the alkyl tails. Perhaps, this can interpret why Gemini surfactants cannot generally enhance the effectiveness in surface tension reduction.

As seen from Table 1, all the $A_{\text {min }}$ of 12-6-8, 12-6-10, 12-6-14, and 12-6-16 are smaller than that of 12-6-12. This phenomenon should also relate to the mechanism discussed above. Lange and Schwuger ${ }^{[15]}$ examined the binary mixture of traditional singlechain surfactants and suggested that two surfactants having the same lengths of the alkyl chains could produced the stronger synergism than those having different lengths of the alkyl chains. 
This means that the present dissymmetric series has a relatively weaker synergism between the two alkyl tails compared with symmetric 12-6-12 and thus smaller concentrated charge effect in the headgroups of dissymmetric series. The decreased electrostatic repulsion between the headgroups results in smaller area of the adsorbed molecule at the air/water interface.

\section{Conclusions}

In this paper, we report a comparative study on the surface activity of symmetric Gemini surfactant series $m-6-m$ with that of the corresponding monomers $\mathrm{C}_{m} \mathrm{TABr}$. Since the length of the hexamethylene spacer of $m-6-m$ is close to the distance between the two headgroups of alkyltrimethylammonium bromides packed on the micelle, $m-6-m$ can be considered as the simple dimer of $\mathrm{C}_{m} \mathrm{TABr}$ in appearance. However, the experimental results show that the surface activity of $m-6-m$ is obviously higher than that of $\mathrm{C}_{m} \mathrm{TABr}$. This fact verifies the existence of the hydrophobic synergism between the alkyl tails of Gemini surfactants very well. Comparatively, the symmetric Gemini surfactants are more favorable for their association and adsorption than the dissymmetric Gemini surfactants.

\section{References}

1 Zana, R.; Xia, J. D. Gemini surfactants. New York: Marcel Dekker
Inc., 2004 and references therein

2 Zana, R.; Benrraou, M.; Rueff, R. Langmuir, 1991, 7: 1072

3 Danino, D.; Talmon, Y.; Zana, R. Langmuir, 1995, 11: 1448

Zana, R. J. Colloid Interface Sci., 2002, 248: 203

Camesano, T. A.; Nagarajan, R. Colloids Surf. A, 2000, 167: 165

6 You, Y.; Zhao, J. X.; Jiang, R.; Cao, J. J. Colloid Polym. Sci., 2009, 287: 839

7 Alami, E.; Beinert, G.; Marie, P.; Zana, R. Langmuir, 1993, 9: 1465

8 Chen, X. D.; Wang, J. B.; Shen, N.; Luo, Y. H.; Li, L.; Liu, M. H.; Thomas, R. K. Langmuir, 2002, 18: 6222

9 Rosen, M. J. Surfactants and interfacial phenomena. 3rd ed. New York: John Wiley \& Sons, 2004: 208-230

10 Ali, M. S.; Suhail, M.; Ghosh, G.; Kabir-ud-Din, M. K. Colloids Surf. A, 2009, 350: 51

11 Fan, Y.; Li. Y.; Cao, M.; Wang, J.; Wang, Y.; Thomas, R. K. Langmuir, 2007, 23: 11458

12 Bai, G. Y.; Wang, J. B.; Wang, Y. L.; Yan, H. K.; Thomas, R. K. J. Phys. Chem. B, 2002, 106: 6614

13 Zana, R. Lamgmuir, 1996, 12: 1208

14 Zana, R. J. Colloid Interface Sci., 1980, 78: 330

15 Lange, H.; Schwuger, J. Kolloid-Z. Z. Polymere, 1971, 243: 120 